\title{
Somatosensory evoked potentials as an objective assessment of the sensory median nerve blockade after infraclavicular block
}

\section{[Les potentiels évoqués somesthésiques comme évaluation objective du bloc sensitif}

du nerf médian après un bloc sous-claviculaire]

Pierre Pandin MD, ${ }^{*}$ Jean Corentin Salengros MD, ${ }^{*}$ Alain d'Hollander MD PhD, † Christiane Tchekap MD, * Arlette Vandesteene $\mathrm{MD} \mathrm{PhD}^{*}$

Purpose: Median nerve somatosensory evoked responses (MnSSER) alterations were compared to clinical tests (cold and pinprick) variations, in 20 ASA I adult patients following infraclavicular block obtained with $40 \mathrm{~mL}$ ropivacaine $0.5 \%$ to assess first, the difference of time course of the respective electrophysiological and clinical signs, and second, the objectivity and the reproducibility of MnSSER changes.

Clinical features: Four MnSSER derivations (Erb's point; cutaneous projection of peripheral end of brachial plexus; posterior neck at $\mathrm{C} 6$ level, frontal and controlateral parietal scalp) were monitored and recorded for retrospective analysis. Continuous data acquisition were started before ropivacaine injection (baseline) and maintained for 30 min thereafter. Every three minutes after ropivacaine injection, cold and pinprick tests were performed in the hand median nerve cutaneous supply zone and were assessed using a sensory visual score (varying from $0-10)$. Data were compared using analysis of variance. Although MnSSER values were stable during baseline period, after ropivacaine administration, severe progressive amplitude depressions of selected MnSSER were detected in every patient. While clinical cold and pinprick tests became positive (score $>8$ ) only $15.8 \pm 1.2 \mathrm{~min}$ and $20.1 \pm 1.8 \mathrm{~min}$ respectively after ropivacaine administration, the mean time to observe the earliest MnSSER 20\% amplitude decrease at Erb's point derivation was reduced to $5.6 \pm \mathrm{I} . \mathrm{I} \mathrm{min}(P<0.0 \mathrm{I})$.

Conclusion: Selected MnSSER amplitude reduction indicates objectively the onset of median nerve anesthesia following infraclavicular brachial plexus block before the appearance of clinical signs.
Objectif : Les modifications des potentiels évoqués somesthésiques du nerf médian (PESNM) induit par un block infraclaviculaire (40 $m L$ de ropivacaine $0,5 \%$ ) on été comparés avec les tests cliniques usuels (tests au froid et à la piqûre) chez 20 patients adultes ASA I afin d'évaluer la différence d'évolution et de survenue des signes électrophysiologiques et cliniques, l'objectivité et la reproductibilité des modifications des PESNM et finalement le possible intérêt en pratique clinique.

Eléments cliniques : Les PESMN étaient enregistrés en continu au point d'Erb (projection cutanée de l'extrémité latérale du plexus brachial) et successivement au niveau cervical en regard de la sixième vertèbre), frontal et pariétal controlatéral pour une comparaison secondaire. L'enregistrement a commencé avant l'injection de ropivacaine et jusqu'à 30 min après. Toutes les trois minutes après la réalisation du bloc, les tests cliniques étaient réalisés au niveau de la main d'innervation du nerf médian en utilisant une échelle visuelle analogique (0-10). Une analyse de variance a été utilisée pour comparer les résultats. Si les PESNM étaient remarquablement stables avant la réalisation du bloc, après leur amplitude diminue précocement et de façon importante, chez tous les sujets. Alors que les tests au froid et à la piqûre peuvent être considérés comme positifs (> 8 sur l'échelle) seulement après 15,8 \pm I,2 min et 20,I \pm I,8 min respectivement après l'injection de ropivacaïne, la diminution la plus précocement détectable de l'amplitude du potentiel (20\%) au point d'Erb, survenait en moyenne en 5,6 \pm $I, I \min (P<0,0 I)$.

Conclusion : La diminution de l'amplitude des PESNM indique objectivement la survenue du bloc du nerf médian après la réalisation d'un bloc infraclaviculaire avant toute modification clinique.

From the Department of Anesthesiology, ${ }^{*}$ Erasmus Hospital, Free University of Brussels, Brussels, Belgium; and the Division of Anesthesiology, Cantonal University Hospital, Geneva, Switzerland.

Address correspondence to: Dr. Pierre C. Pandin, Department of Anesthesiology and Intensive Care, Erasmus Hospital, Lennik Drive 808,

B-1070 Brussels, Belgium. Phone: +32-2-555-39-19; Fax: +32-2-555-43-63; E-mail: ppandin@ulb.ac.be

Assessed January 19, 2005

Accepted for publication June 23, 2005.

Revision accepted July 19, 2005. 


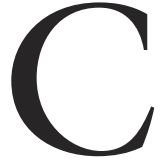

LINICAL assessment of the onset and extent of sensory block during regional anesthesia can be a challenging task. The problem of subjectivity in both perception and expression of sensory block is unresolved, justifying the proposal of an "ideal multimodal testing sequence" based on recently compiled methods. ${ }^{1}$ Swelling illusion ${ }^{2}$ can be an alternative, but unfortunately is sometimes difficult to understand by some patients. Somatosensory evoked potential (SSEP) monitoring either for peripheral nerve block ${ }^{3-6}$ and iv regional anesthesia ${ }^{7}$ or for epidural anesthesia ${ }^{8}$ has the potential to provide an objective assessment of nerve block. Nevertheless, preliminary results cannot necessarily be extrapolated to clinical practice. Our study was thus designed: first, to describe the effect of ropivacaine, on the brachial plexus using the infraclavicular approach, guided by median nerve somatosensory evoked responses (MnSSER) and second, to monitor clinically the sensory visual analogue score (SVAS) variations $^{2}$ in response to cold and pinprick tests applied in the hand's median nerve cutaneous supply zone. We postulated that the median nerve blockade onset in the brachial plexus can be anticipated by quantitative variations of MnSSER recordings.

\section{Material and method \\ Patient selection}

After giving written informed consent, nine males and 11 females non obese patients (18-42 yr old, ASA class I), were enrolled in this study approved by the Local Authors Institutional Human Investigation Committee (Erasmus Hospital in Brussels, Belgium). After alprazolam $0.5 \mathrm{mg}$ po given one hour before anesthesia, no other sedative or analgesic drug was used before, during or after the block initiation until study completion.

Median nerve somatosensory evoked response recordings Before baseline and for $30 \mathrm{~min}$ after the ropivacaine administration, the median nerve was stimulated at the wrist (frequency $1 \mathrm{~Hz}$ and duration $0.2 \mathrm{msec}$ ) using the electrical stimulator of an Epoch $2000^{\mathrm{TM}}$ (Axon Systems Inc, San Francisco, CA, USA). The stimulation intensity was decreased by $2 \mathrm{~mA}$ when the evoked muscular twitches were observed (between 12 and 17 $\mathrm{mA}$ ). Somatosensory evoked responses were recorded from sc needle electrodes at Erb's point (cutaneous projection of the peripheral end of the brachial plexus $2-3 \mathrm{~cm}$ above the clavicle), designated as "Erb"; from the cervical spine (just above the cutaneous projection of the spinous process of the sixth cervical vertebrae) designated as "C6" - and at the scalp, at the median prefrontal level (Fpz)- designated as "Fpz" and at the contralateral parietal level (P'4) - designated as "P'4". A common reference electrode (positive pole) was positioned on the ipsilateral ear designated as " $\mathrm{A}$ ". All electrode impedances were automatically checked for values less than $5 \mathrm{kOhms}$. The recording frequency bandpass was 30 to $750 \mathrm{~Hz}$ and the sampling window $50 \mathrm{msec}$. Artifact rejection threshold was fixed at 25 $\mu \mathrm{V}$. The $50 \mathrm{~Hz}$ notch filter was active.

\section{Median nerve somatosensory evoked responses data acquisition methodology}

Monitored MnSSER were respectively: P10, a peak present $10 \pm 0.5 \mathrm{msec}$ after stimulation, in A-Erb derivation; $\mathrm{Pll}$, at $11 \pm 0.5 \mathrm{msec}$ in the $\mathrm{A}-\mathrm{C} 6$ derivation; N20, at $20 \pm 0.5 \mathrm{msec}$ in the controlateral A-P'4 derivation and $\mathrm{P} 22$, at $22 \pm 0.5 \mathrm{msec}$ in the $\mathrm{A}-\mathrm{Fpz}$ derivation. Before acquisition of baseline measurements, three groups of 500 averaged responses were required to assess a good visual reproducibility of evoked potential recordings. Triplicate MnSSER baseline measurement acquisitions were then performed approximatively five minutes prior to the ropivacaine injection. The average of the amplitude and latency values obtained (labelled " $t_{-5}$ ") were used as reference for subsequent comparison. Immediately after the ropivacaine injection (labelled " $t_{0}$ ") and during the next $30 \mathrm{~min}$, the averaging technique was applied continuously to obtain the MnSSER responses every 100 sweeps (MnSSER every 15-20 sec). The pre- and post-ropivacaine administration previously defined signals were automatically saved for retrospective analysis from each recording site. Besides manual retrospective analysis, the automatic tracker software of our monitoring system was able to detect, from baseline values, a $20 \%$ variation either in amplitude or in latency, widely accepted as the correct threshold for significant changes. The maximal electrophysiological effect, based on a non-automated analysis by a blinded observer, was defined as an evoked response amplitude of less than $0.5 \mu \mathrm{V}$ present in three successive averaging periods.

\section{Infraclavicular brachial plexus block}

The infraclavicular block was performed following the Raj's approach. ${ }^{9}$ After local anesthesia, a 10-cm long, short bevel insulated needle (Stimuplex $\mathrm{A}^{\mathrm{TM}}$, BBraun Inc., Melsungen, Germany) connected to the negative pole of a nerve stimulator (Stimuplex HNS $11^{\mathrm{TM}}$ BBraun Inc., Melsungen, Germany - $100 \mu$ sec pulse width, $1.5 \mathrm{~mA}$ initial current intensity at $1 \mathrm{~Hz}$ ), was inserted. After median nerve location (muscular twitches corresponding to wrist, second and third 
TABLE I Somatosensory evoked responses before and after ropivacaine

\begin{tabular}{|c|c|c|c|c|c|c|c|}
\hline & \multicolumn{4}{|c|}{$\begin{array}{l}\text { Baseline records } \\
\text { "Reproducibility of baseline MnSSERs" }\end{array}$} & \multicolumn{3}{|c|}{$\begin{array}{l}\text { Ropivacaine injection } \\
\text { "Local physical effect of ropivacaine" }\end{array}$} \\
\hline & $\begin{array}{l}\text { Baseline } \\
\text { Run (1) }\end{array}$ & $\begin{array}{l}\text { Baseline } \\
\text { Run (2) }\end{array}$ & $\begin{array}{l}\text { Baseline } \\
\text { Run (3) }\end{array}$ & $\begin{array}{l}\text { One way } \\
\text { ANOVA }\end{array}$ & $t_{-5}$ & $t_{0}$ & $\begin{array}{l}\text { One Way } \\
\text { ANOVA }\end{array}$ \\
\hline \multicolumn{8}{|l|}{ Mean amplitudes $(\mu V)$} \\
\hline PlO & $4.1 \pm 0.8$ & $3.9 \pm 0.9$ & $4.2 \pm 0.7$ & $P=0.49$ & $4.1 \pm 0.6$ & $4.3 \pm 0.7$ & $P=0.68$ \\
\hline P11 & $1.6 \pm 0.7$ & $1.4 \pm 0.6$ & $1.7 \pm 0.5$ & $P=0.49$ & $1.5 \pm 0.5$ & $1.3 \pm 0.5$ & $P=0.51$ \\
\hline $\mathrm{N} 20$ & $2.9 \pm 0.7$ & $2.9 \pm 0.6$ & $3.1 \pm 0.4$ & $P=0.46$ & $2.9 \pm 0.3$ & $2.7 \pm 0.5$ & $P=0.57$ \\
\hline $\mathrm{P} 22$ & $2.1 \pm 0.6$ & $2.1 \pm 0.7$ & $1.9 \pm 0.6$ & $P=0.52$ & $2.0 \pm 0.8$ & $2.1 \pm 0.5$ & $P=0.66$ \\
\hline \multicolumn{8}{|l|}{ Mean latencies (msec) } \\
\hline $\mathrm{P} 10$ & $9.7 \pm 0.7$ & $10.2 \pm 0.8$ & $10.1 \pm 0.6$ & $P=0.68$ & $10.1 \pm 0.6$ & $10.3 \pm 0.4$ & $P=0.69$ \\
\hline Pll & $11.3 \pm 0.4$ & $11.1 \pm 0.8$ & $10.9 \pm 0.7$ & $P=0.56$ & $11.1 \pm 0.7$ & $11 \pm 0.5$ & $P=0.71$ \\
\hline $\mathrm{N} 20$ & $20.1 \pm 0.8$ & $20.2 \pm 0.7$ & $19.8 \pm 0.8$ & $P=0.53$ & $20.1 \pm 0.6$ & $20.3 \pm 0.9$ & $P=0.59$ \\
\hline $\mathrm{P} 22$ & $21.9 \pm 0.7$ & $22.3 \pm 0.6$ & $22.1 \pm 0.7$ & $P=0.47$ & $22.1 \pm 0.8$ & $22.2 \pm 0.6$ & $P=0.68$ \\
\hline \multicolumn{8}{|c|}{$\begin{array}{l}\text { Median nerve somatosensory evoked responses (MnSSERs) during baseline records (four columns on right including ANOVA compari- } \\
\text { son) and before and after the ropivacaine injection (three columns on left including ANOVA comparison). Results are expressed as mean } \\
\text { values } \pm \text { standard deviation. For the baseline records, mean amplitude and latency values of each MnSSER have been calculated from the } \\
\text { respective } 20 \text { individual values. The statisqtical comparison of these averages relates the stability and the reproducibility of these evoked } \\
\text { potentials. For the ropivacaine injection physical effect, the mean amplitudes and latencies of the respective waves prior to the injection ( } t \text { - } \\
\text { 5) correspond to the average of the three successive baseline mean values (baseline run } 1-3 \text { ). They have been considered as baseline values } \\
\text { for further comparison. Just after the ropivacaine injection }\left(t_{0}\right) \text {, mean amplitudes and latencies have been calculated from the respective } 20 \\
\text { individual values at } t_{0} \text {. The statistical comparison between } t_{-5} \text { and } t_{0} \text { demonstrates the lack of local physical effect of the ropivacaine solu- } \\
\text { tion on the MnSSER recordings. }\end{array}$} \\
\hline
\end{tabular}

finger flexion and forearm pronation), with a minimal stimulation current intensity of $0.5 \mathrm{~mA}, 40 \mathrm{~mL}$ of ropivacaine $0.5 \%$ were injected.

\section{Clinical assessment of sensory blockade}

After ropivacaine administration, cold and pinprick tests were performed every three minutes to assess anesthesia on the palmar face of the base of the second and third fingers (median nerve cutaneous supply zone). The patient documented his/her perceptions according to a SVAS, similarly to the Benzon's method. ${ }^{3}$ The scale consisted of a $10-\mathrm{cm}$ line, where the 0 $\mathrm{cm}$ mark stated "my cutaneous zone is not numbed at all", while $10 \mathrm{~cm}$ corresponded to "my cutaneous zone is completely numbed"; scores less than 1 were matched as a "no block" whereas those higher than 8 as "a good and effective block". The latter score was considered adequate for quatifying the clinical effectiveness of the block. Following cold or pinprick stimulation, we obtained cold SVAS (cSVAS) or pinprick SVAS (pSVAS), respectively.

\section{Data analysis}

Mean values of amplitude and latency of each MnSSER (P10, P11, N20 and P22) at time $t_{-5}$ where considered as baseline values. The MnSSER waves, registered before and immediately after each SVAS clinical assess- ment performed every three minutes from $t_{0}$ to $t_{30}$, were extracted from the raw data and averaged. The parameters produced every three minutes after ropivacaine administration therefore consisted of mean MnSSER amplitudes and latencies, cSVAS and pSVAS values.

For statistical analysis, one way and repeated measures ANOVA tests were used (Instat $3.05^{\mathrm{TM}}$ and Prism $3.03^{\text {TM }}$ softwares - Graph Pad Software Inc, San Diego, CA, USA).

The analysis permitted: 1) evaluation of individual stability and reproducibility of the baseline MnSSER by comparison of the respective amplitudes and latencies of baseline evoked potentials from the three initial averages of 500 sweeps to confirm the initial on-line visual inspection of the profiles of the different waves; 2) testing the existence or not of a possible bias induced by the physical effect of the $40 \mathrm{~mL}$ anesthesia solution injection, by comparing the mean amplitudes and latencies of each monitored MnSSER at baseline and $t_{0}$ (just after the injection) and; 3 ) the time evolution of amplitude and latency of each MnSSER and the two SVAS scores. The results are presented as mean \pm SD. A $P$ value $<0.05$ was considered statistically significant. 

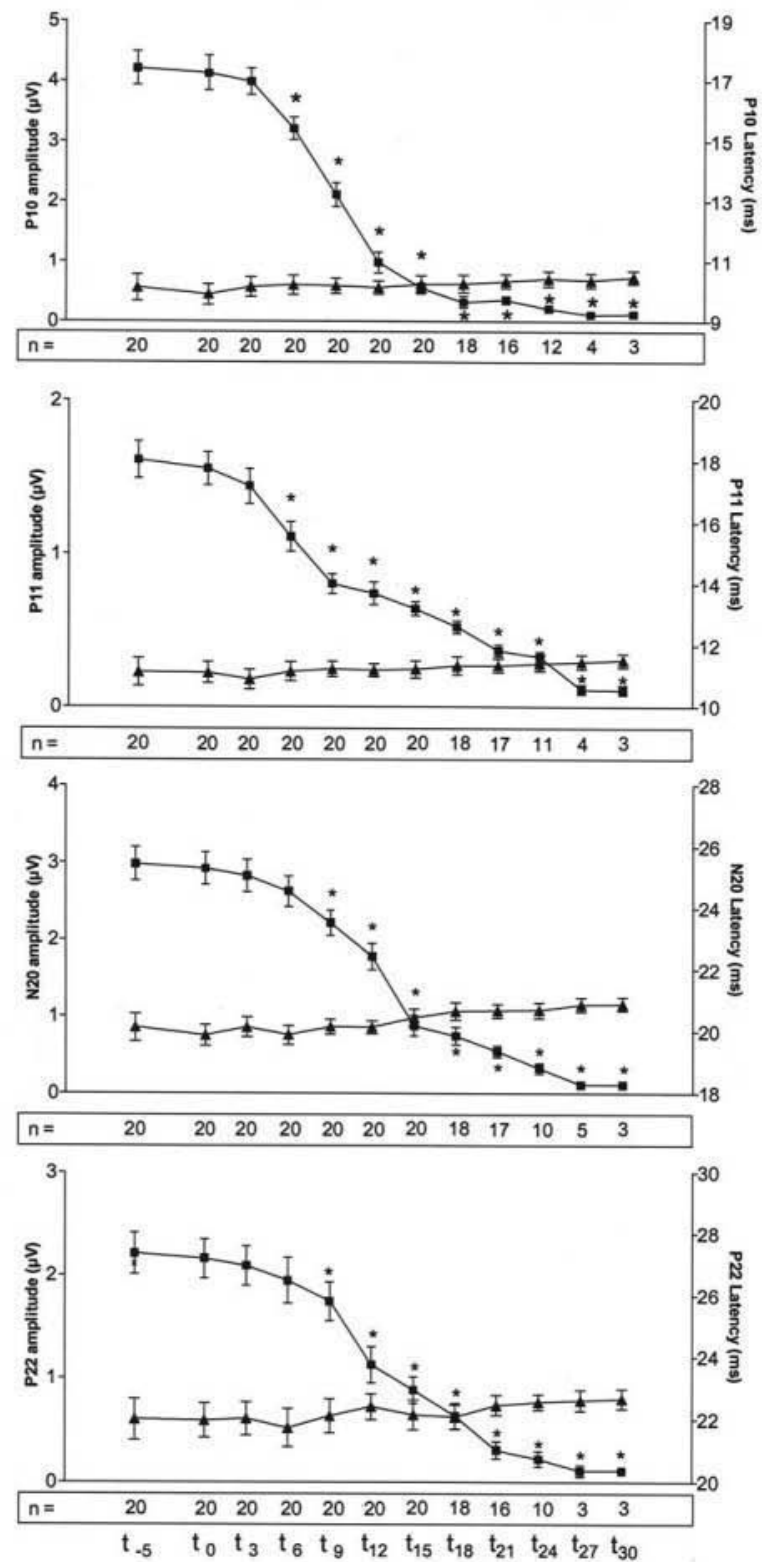

FIGURE 1 Changes of median nerve somatosensory evoked responses (MnSSER; P10, P11, N20, P22) amplitudes (black squares) and latencies (black triangles) over time. The successive amplitude values of each MnSSER were compared to the respective initial one (baseline) using one way ANOVA $\left({ }^{*} P<0.05\right)$. The number of patients with recordable amplitude signal $(>0.5 \mu \mathrm{V})$ is indicated in the rectangular area located at the bottom of each figure.
TABLE II Sensory visual analogue scores

\begin{tabular}{lll}
\hline & Delays (min) & One way ANOVA \\
\hline P10 & $5.6 \pm 1.1$ & - \\
P11 & $5.8 \pm 1.3$ & $P=0.60$ \\
N20 & $7.6 \pm 1.3$ & $P=0.021$ \\
P22 & $8.4 \pm 1.4$ & $P=0.026$ \\
cSVAS & $15.8 \pm 1.2$ & $P=0.0081$ \\
pSVAS & $20.1 \pm 1.8$ & $P=0.0093$ \\
\hline
\end{tabular}

SVAS = sensory visual analogue scale. Mean delays for the recording of a detectable and readable automatic $20 \%$ amplitude decrease for P10, P11, N20, P22 and the observation of equal or greater than 8 cSVAS and pSVAS (left column; results are presented as mean value \pm SD). For statistical analysis (right column), the different delays observed were all compared to the delay observed for P10.

\section{Results}

Regional anesthesia procedure

Infraclavicular block was successfully performed in all 20 patients by five different anesthesiologists. The neural blockade obtained was effective in the median nerve supply, as well as regions of the ulnar and the radial nerves, allowing the scheduled surgery. The mean infraclavicular block duration was $6.2 \pm 0.6 \mathrm{~min}$ (time elapsed between local anesthesia and end of the ropivacaine injection). During the study period, the plexus block failed to occur (no median nerve block) in three patients from the 20 included, in spite of the correct median nerve stimulation. In these three patients, no changes were recorded. Our comparison between electrophysiological and clinical assessment of the nerve block was based only on successful blocks.

\section{Electrophysiological signal variations}

The mean time to install the MnSSER equipment set and electrode insertion was $5.3 \pm 0.4 \mathrm{~min}$.

Values and reproducibility of baseline measurements Before ropivacaine administration, mean MnSSER amplitudes and latencies recorded in three consecutive runs were stable (one-way ANOVA; NS) and documented normal baseline numerical values (Table I).

\section{Lack of immediate physical effects of $40 \mathrm{~mL}$ ropiva- caine administration}

Comparison of mean amplitude and latency values of P10, P11, N20 and P22 before and just after anesthetic solution injection did not demonstrate any difference (Table I) whatever the MnSSER considered (one way ANOVA, NS). 


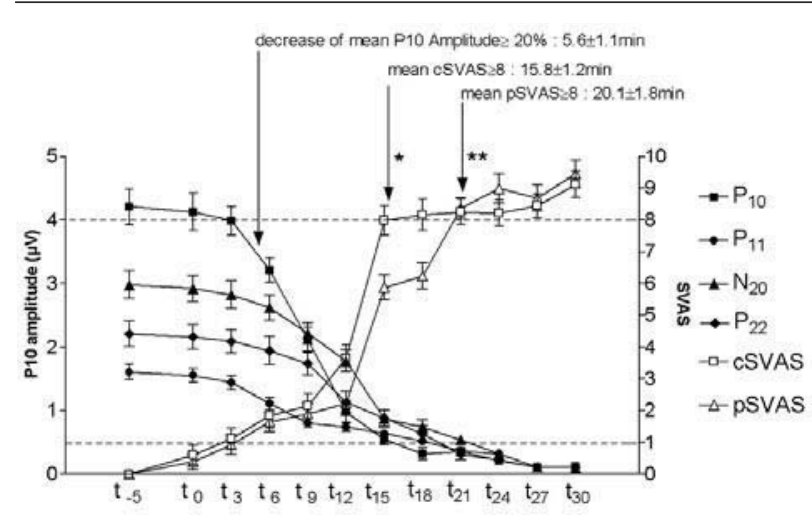

FIGURE 2 Time evolution of the cSVAS (white square) and pSVAS (white triangle). Lower horizontal dot line matches for threshold of clinically absent nerve block (score $<1$ ), while the upper one corresponds to the presence of an effective block (score $>8$ ).

Median nerve somatosensory evoked responses amplitude and latency evolution after ropivacaine administration Figure 1 depicts the evolution of mean amplitude and latency of the MnSSER over the time from baseline $\left(t_{-5}\right)$ until $30 \mathrm{~min}$ after local anesthetic injection. Independently from the MnSSER, mean amplitudes have decreased progressively and significantly until they became very often undetectable. A significant reduction in peripheral MnSSER (P10 and P11) was observed faster than in central ones (N20 and P22 Table II and Figure 1). Table II summarizes the time elapsed after ropivacaine administration and the standard 20\% amplitude decrease observed at P10, Pl1, $\mathrm{N} 20$ and P22. N20 and P22 alteration times were different compared to the P10 delay $(P=0.021$ and $P$ $=0.026$, one way ANOVA, respectively).

\section{Sensory visual analogic score and clinical block}

Assessment of the mean time elapsed for confirming the clinical signs of a valuable median nerve block (corresponding to a cSVAS or a pSVAS score $\geq 8$ ) showed mean delays of $15.8 \pm 1.2$ min for cold and after 20.1 $\pm 1.8 \mathrm{~min}$ for pinprick tests (Table II and Figure 2).

\section{Comparison between MnSSER and SVAS}

The differences between the delays documented with MnSSER recordings and the clinical criteria for establishment of median nerve block are presented in Table II (for comparison between PI0 and cSVAS or a pSVAS). A difference of about ten minutes was observed between the P10 20\% decrease time, and cSVAS $(P=0.0081$, one way ANOVA); for pSVAS, the mean supplementary waiting delay increased to 14 $\min (P=0.0093$, one way ANOVA $)$.

\section{Discussion}

Somatosensory evoked potentials are effective to qualify and/or quantify the occurrence and time course of electrophysiological changes associated with neural block induced by local anesthetics. ${ }^{3-8}$ Nevertheless, previous studies have not been able to identify direct clinical applications. Consequently, the goal of our study was to describe the MnSSER alterations indicating a successful median nerve block of the brachial plexus by adapting Benzon's ${ }^{3}$ methodology in surgical patients. The median nerve was preferred because the ease of its location by the infraclavicular approach ${ }^{10}$ using a single injection technique, verifying optimal position of the needle tip near the brachial plexus. ${ }^{9}$

Consistent with other published data, ${ }^{3,7}$ no significant changes in the latencies were observed, but depression of MnSSER amplitude in the diverse channels appears as a good indice for detecting the onset and the progression of a chemically induced neural blockade. In the present context, (quantification with a possible anticipation of a potentially successful neural blockade), it seems evident that limited amplitude reduction (by 20\%) is a good clinical indicator. Each time a $20 \%$ amplitude reduction is observed, the MnSSER will eventually disappear, indicating effective median nerve blockade. The $20 \%$ value was chosen because the default tracking method of our monitoring system permitted an automatic detection of MnSSER alterations. However, for a human observer, the depression of amplitude and its time course can be more easily noticed and detected on the peripheral MnSSER collected at Erb's point, as their initial amplitudes $(3-5 \mu \mathrm{V})$ are always higher than the ones recorded more centrally $(<2.5-3 \mu \mathrm{V})$. On the Erb's point derivation, the detection occurred during the early phase (ranging between three to six minutes) of the ropivacaine induced block.

An unresolved issue is whether or not SSEP assessment of one brachial plexus nerve is sufficient to conclude that the plexus block will be complete. Based upon our experience, we think "no". Although MnSSER can detect objectively the early occurrence of an effective brachial plexus block compared to clinical assessment, the correlation between median nerve location and plexus anatomy is variable. Accordingly, a more systematic SSEP investigation of median, ulnar and radial nerves during brachial plexus block techniques (not only infraclavicular, but also axillary, interscalene and subclavicular) may simplify the technique and clarify its usefulness in clinical practice. 
In conclusion, MnSSER monitoring in adult patients permits objective quantification of the onset of clinical median nerve blockade after $40 \mathrm{~mL}$ of $0.5 \%$ ropivacaine for brachial plexus blockade. The P10 amplitude decrease is always associated with a clinically successful block, and appears about ten minutes earlier than the clinical confirmation of median nerve block. This electrophysiologically-based, pain-free monitoring may be important in clinical anesthesia, and provides a method for studying more objectively the clinical action of local anesthetic solutions.

\section{References}

1 Curatolo M, Petersen-Felix S, Arendt-Nielsen L. Sensory assessment of regional analgesia in humans: a review of methods and applications. Anesthesiology 2000; 93: 1517-30.

2 Paqueron X, Gentili ME, Willer JC, Coriat P, Riou B. Time sequence of sensory changes after upper extremity block: swelling sensation is an early and accurate predictor of success. Anesthesiology 2004; 101: 162-8.

3 Benzon HT, Toleikis JR, Shanks C, Ramseur A, Sloan T. Somatosensory evoked potential quantification of ulnar nerve blockade. Anesth Analg 1986; 65: 843-8.

4 Richardson J, Jones J, Atkinson R. The effect of thoracic paravertebral blockade on intercostal somatosensory evoked potentials. Anesth Analg 1998; 87: 373-6.

5 Murphy BA, Haavik Taylor H, Wilson SA, Knight JA, Mathers KM, Schug S. Changes in median nerve soamtosensory transmission and motor output following transient deafferentation of the radial nerve in humans. Clin Neurophysiol 2003; 114: 1477-88.

6 Weiss T, Miltner WH, Liepert J, Meissner W, Taub E. Rapid functional plasticity in the primary somatomotor cortex and perceptual changes after nerve block. Eur J Neurosci 2004; 20: 3413-23.

7 Lang E, Erdmann K, Gerbershagen HU. Median nerve blockade during diagnostic intravenous regional anesthesia as measured by somatosensory evoked potentials. Anesth Analg 1993; 76: 118-22.

8 Benzon HT, Toleikis JR, Dixit P, Goodman I, Hill JA. Onset, intensity of blockade and somatosensory evoked potential changes of the lumbosacral dermatomes after epidural anesthesia with alkalinized lidocaine. Anesth Analg 1993; 76: 328-32.

9 Raj PP, Montgomery SJ, Nettles D, Jenkins MT. Infraclavicular brachial plexus block - a new approach. Anesth Analg 1973; 52: 897-904.

10 Borene SC, Edwards JN, Boezaart AP. At the cords, the pinkie towards: interpreting infraclavicular motor responses to neurostimulation. Reg Anesth Pain Med 2004; 29: 125-9. 